\title{
Volcanic constructs on Ganymede and Enceladus: Topographic evidence from stereo images and photoclinometry
}

\author{
Paul M. Schenk \\ Lunar and Planetary Institute, Houston, Texas \\ Jeffrey M. Moore \\ Space Sciences Division and the SETI Institute, NASA Ames Research Center, Moffett Field, California
}

- Abstract. The morphology of volcanic features on Ganymede differs significantly from that on the terrestrial planets. Few if any major volcanic landforms, such as thick flows or shield volcanoes, have been identified to date. Using new stereo Voyager images, we have searched Ganymede for relief-generating volcanic constructs. We observed seven major types of volcanic structures, including several not previously recognized. The oldest are broad flat-topped domes partially filling many older craters in dark terrain. Similar domes occur on Enceladus. Together with smooth dark deposits, these domes indicate that the volcanic history of the dark terrain is complex. Bright terrain covers vast areas, although the style of emplacement remains unclear. Smooth bright materials embay and flood older terrains, and may have been emplaced as lowviscosity fluids. Associated with smooth bright material are a number of scalloped-shaped, semienclosed scarps that cut into preexisting terrain. In planform these structures resemble terrestrial calderas. The youngest volcanic materials identified are a series of small flows that may have flooded the floor of the multiring impact structure Gilgamesh, forming a broad dome. The identification of volcanic constructs up to $1 \mathrm{~km}$ thick is the first evidence for extrusion of moderate-to-high viscosity material on Ganymede. Viscosity and yield strength estimates for these materials span several orders of magnitude, indicating that volcanic materials on Ganymede have a range of compositions and/or were extruded under a wide range of conditions and/or eruptive styles.

\section{Introduction}

The Voyager survey of the outer solar system has revealed an astonishing variety of endogenic landforms on the surfaces of icy satellites. Despite extensive endogenic resurfacing of some satellites, for example, Ganymede, Enceladus, and Triton, volcanism on these surfaces has little topographic expression. We do not see massive volcanic edifices similar to Olympus Mons or Mauna Kea. Even the best putative examples of volcanic landforms, seen on Ariel, Miranda, Triton, and Enceladus, exhibit rarely more than $1-2 \mathrm{~km}$ of relief [Jankowski and Squyres, 1988; Pozio and Kargel, 1989; Schenk, 1991a; Croft et al., 1995]. This may be related to the "soft" rheology of ice (see Poirier [1982], Durham et al. [1983], and Kirby et al. [1987]), or to rheology and volcanic styles peculiar to icy petrologic systems [e.g., Kargel, 1991; Kargel et al, 1991].

Well over half of the surface of Ganymede (radius $2634 \mathrm{~km}$ ) has been covered by endogenic effusions. It is now considered likely that Ganymede experienced one or more episodes of chaotic orbital behavior [Malhotra, 1991], possibly resulting in tidal heating. Volcanic resurfacing constitutes a record of Ganymede's compositional and thermal evolution and may record some of these putative tidal heating events. Yet this satellite has been the subject of morphological study for 15 years without the unambiguous detection of relief-

Copyright 1995 by the American Geophysical Union.

Paper number 95JE01854.

$0148-0227 / 95 / 95 \mathrm{JE}-01854 \$ 05.00$ generating volcanic constructions on its landscape. The style of emplacement and composition of those volcanic deposits that have been identified remains unclear.

On any planetary surface, volcanic and other nonimpact constructs can be difficult to recognize in spacecraft images, particularly those obtained under high Sun conditions [e.g., Malin, 1978]. Topography is especially low on the Galilean satellites, and imaging resolution is at best $-500 \mathrm{~m} /$ pixel. Major local albedo variations on Ganymede further complicate geologic and topographic mapping. With these problems in mind, we have undertaken the production of stereo pairs of Voyager images (where coverage permits) to aid in the search for and characterization of volcanic landforms on Ganymede's surface. In addition to an examination of previously identified volcanic materials, we report the discovery of several previously unrecognized volcanic landforms and at least two types with substantial relief, and describe their morphology and geologic setting. Morphology of volcanic deposits indicates that Ganymede extrusions probably had a range of rheologies and may be compositionally variable. We conclude with speculations and predictions regarding their mode of emplacement and the implications of volcanic landforms for the geologic evolution of Ganymede.

\section{Stereo Imaging with Voyager}

This study was motivated by the recognition that a significant fraction of the surfaces of most of the outer planet satellites were imaged by Voyager in stereo [e.g., Croft and Soderblom, 1991; Schenk and Moore, 1993]. We can use stereo imaging to detect subtle topographic features that were 
previously unrecognized, and to better characterize known structures, particularly when high solar illumination reduces our ability to perceive topography. Because of substantial variations in resolution and viewing geometry between images, several steps were necessary to produce useful stereo products. Following radiometric calibration, a sharpening filter was applied to enhance detail. Precision geometric control of the Ganymede images is required for stereo. Pointing was updated using match points between overlapping images. Once controlled, images were projected into a common map format, in this case orthographic projections at common scales centered on the feature of interest. A $401 \times 401$ high-pass filter was applied to remove regional brightness gradients for uniform scene contrast.

On Ganymede, overlapping image sequences taken 1-2 hours apart by Voyager 2 provide nearly continuous stereo coverage from $30^{\circ} \mathrm{N}$ to $90^{\circ} \mathrm{S}$ in a swath $\sim 25^{\circ}$ wide centered on $132^{\circ} \mathrm{W}$ longitude (several isolated stereo pairs are located west of these mosaics and near the north pole). Resolution in this swath varies from 1 to $0.5 \mathrm{~km} /$ pixel from north to south. More important, the divergence angle between the camera observing positions varied from $14^{\circ}$ to $59^{\circ}$, and the base-toheight $(b / h)$ ratio varied from 0.4 to 1.2 , from north to south. This variability is a consequence of the imaging sequences, which were not targeted for stereo coverage. Nevertheless, $-20 \%$ of the surface of Ganymede was observed in stereo, including samples of all major terrain and crater types.

The degree to which relief is visible and the precision of stereoscopic measurements of relief in planetary stereo images are a function of the $b / h$ ratio, and the amount of relief present. For Ganymede, $b / h$ is typically less than $\sim 1$, low relative to terrestrial air photos. This is compounded by the inherently low relief of the surface of Ganymede. Fresh crater depths do not exceed $\sim 2 \mathrm{~km}$ [Schenk, 1991b]. Furrow and groove structures have even less relief [e.g., Squyres, 1981]. Nevertheless, automatic stereo correlation routines are capable of producing useful topographic maps of broad-scale features on Ganymede. For local slope and height determinations, we supplement our stereo mapping with established photoclinometry techniques (as used by Schenk [1989]). Despite these limitations, topographic relief was easily discerned on Ganymede in our stereo images. Several topographically distinct volcanic landforms on Ganymede are recognizable in these data products.

\section{Previous Work}

Since 1979 , a variety of materials on Ganymede have been proposed to be volcanic. The surface is roughly equally divided into bright and dark terrains [Smith et al., 1979a, b]. Bright terrain has a relatively high albedo, low crater density, and a superpositional relationship with dark terrain, indicating bright terrain is younger and may have a somewhat different composition. These observations led Smith et al. to attribute bright terrain to endogenic resurfacing. Current models of cratering fluxes [Shoemaker, 1994; personal communication, 1995] suggest that bright terrains may be a young as 1 b.y. old.

Most investigators favor $\mathrm{H}_{2} \mathrm{O}$ as the principle volcanic constituent responsible for bright terrain resurfacing [e.g., Allison and Clifford, 1987]. There is, however, no direct evidence to distinguish whether bright terrain materials were emplaced as a liquid or in the solid-state (or both), and whether they were emplaced as many successive flows or a few massive flows. Flow fronts have not yet been confidently identified. Shoemaker et al. [1982] mentioned extrusion in a list of possible mechanisms which might form some individual ridges in grooved terrain, but this idea was not further developed.

Irregular smooth dark units of uncertain origin have also been reported interspersed within ancient dark terrain by Casacchia and Strom [1984] and Murchie et al. [1990]. Both groups ascribe these patchy smooth units to ancient volcanism. Diffuse "wispy" bright materials, seen in a few locations within dark terrain, have been interpreted as remnant palimpsests [Shoemaker et al., 1982], or as pyroclastic deposits [Helfenstein, 1986].

Several early post-Voyager studies discussed possible examples of discrete volcanic landforms on Ganymede associated with ice volcanism, some of which may be associated with impact structures. Squyres [1980] evaluated ice volcanism and isostatic upwarping as two possible formation mechanisms for a broad topographic dome a few hundred kilometers across. Squyres concluded that perhaps both processes operated but was unable to determine which was dominant. At least three of these structures are known, all of which are characterized by impact ejecta deposits and secondary craters.

Bright domes situated within the central pits of large craters on Ganymede and Callisto have been attributed to postimpact solid-state ice-diapirism [Malin, 1980; Moore and Malin, 1988], or alternatively, to the rapid uplift and exposure of bright, low-viscosity deep-seated material during impact [Schenk, 1991b]. Impact triggered volcanic extrusion was proposed as an explanation for palimpsest formation by Thomas and Squyres [1990].

Lucchitta [1980] noted, without elaboration, the presence of several arcuate-to-semi-enclosed depressions approximately $50 \mathrm{~km}$ across, which exhibit scalloped traces in detail. She described these as "caldera-like." Allison and Clifford [1987] described one of these structures as an "ice-flooded crater." Geologic mapping of Ganymede at 1:5,000,000 under the aegis of the U. S. Geological Survey classified these calderalike depressions as "irregular depressions" and "sinuous rilles (troughs)" [Wilhelms, 1995], and they were interpreted as sites of water eruption and flow.

\section{Observations}

\section{Crater Floor Domes-Ganymede}

A significant number of craters on Ganymede appear to be flattened [Smith et al., 1979a, b], an observation usually attributed to viscous relaxation [e.g., Johnson and McGetchin, 1973]. Within Galileo Regio, the largest preserved block of dark terrain, some of these flattened craters are visible in stereo. Stereo examination of these craters reveals that many are in fact not flattened but instead are partially filled by broad convex domes (Figure 1). These crater floor domes appear to be surrounded by a narrow trench or groove (Figure 2), of which the inner walls are the relatively steep outer slopes of the floor domes, and the outer walls are the crater rim walls. Small pit(s) are visible near the crest of many of the larger domes. These pits are often offset from the center and/or elongated (Figure 3), unlike the pits of central pit 

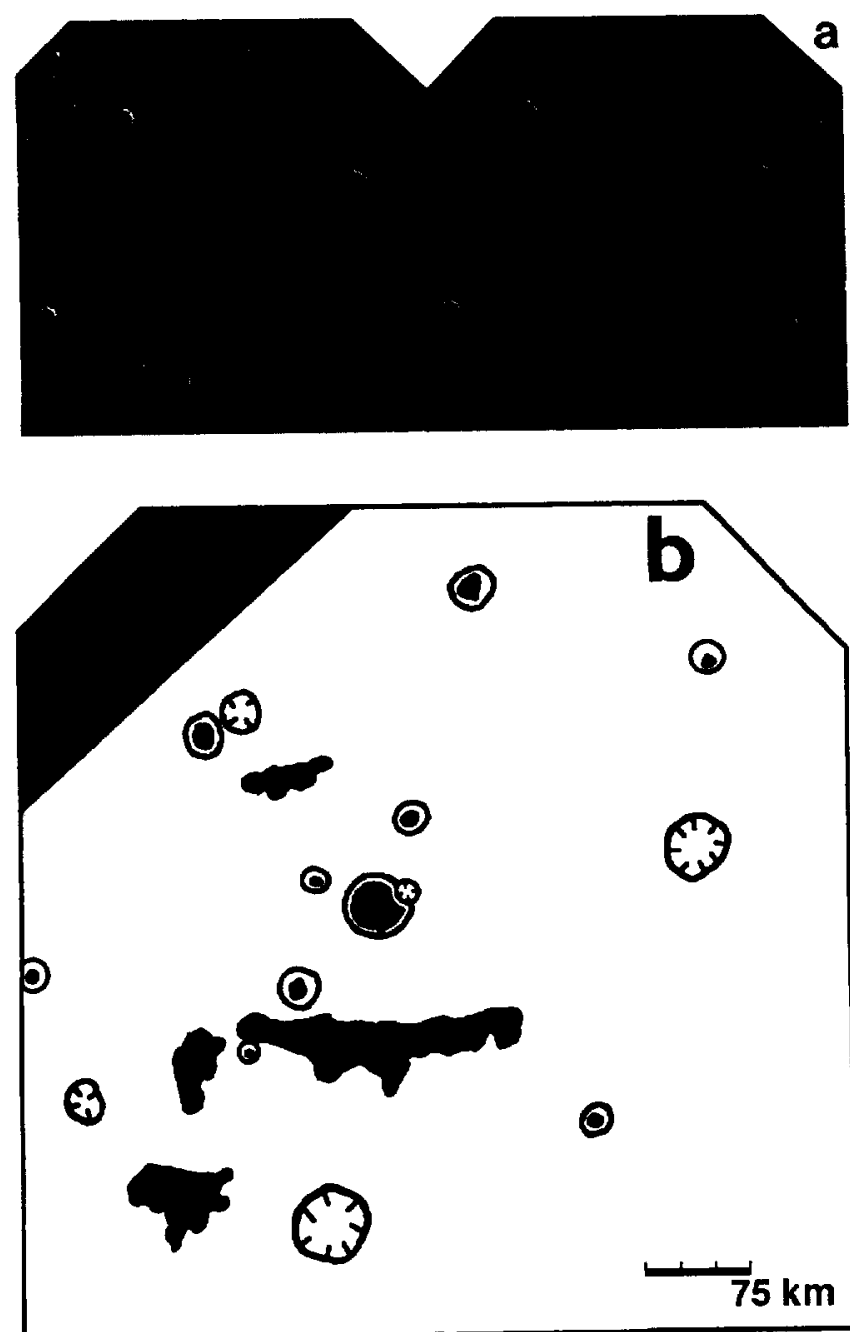

Figure 1. (a) Voyager stereo pair and (b) geologic sketch map of crater floor domes and dark smooth material in Galileo Regio. Several prominent, irregular crater floor domes are indicated (circular dark patches in b). Dark smooth material appears to embay fractured plains (dark patches in Figure 1b). Images centered on $24^{\circ} \mathrm{N}, 128^{\circ} \mathrm{W}$. Stereo convergence angle is $13^{\circ}$, vertical exaggeration is 2 .

craters [Passey and Shoemaker, 1982]. We have observed no instances of crater floor domes overlapping or breaching crater walls. Crater floor domes have been identified in craters as small as $10 \mathrm{~km}$, and are found in roughly $30 \%$ of all craters larger than $10 \mathrm{~km}$ in the eastern half of Galileo Regio (where Sun illumination was low during Voyager imaging). The largest known domes are $-40 \mathrm{~km}$ across.

Dome-filled craters on Ganymede were originally identified as viscously relaxed craters [e.g., Passey and Shoemaker, 1982]. Our observations suggest that a new interpretation is required. Some domes cover only a portion of the crater floor and are offset from the crater center (Figure 3). In several cases, these domes have lobate indentations and protrusions that do not match the adjacent crater rim. Domes have topographically distinct margins with slopes of $10^{\circ}$ to $20^{\circ}$, estimated photoclinometrically. Stereo images and photoclinometry both indicate that the depths of these craters (from rim crest to the base of the rim wall) are 0.5 to $1 \mathrm{~km}$ (Figure 4), similar to fresh unfilled craters of this size [Schenk, 1991b].
The crests of the floor domes are at elevations roughly similar to the crater rims. The depths and topographic profiles across these craters (Figure 4) are inconsistent with those expected for relaxed craters [e.g., Hillgren and Melosh, 1989; Thomas and Schubert, 1988]. Specifically, these models fail to predict the deep bounding trenches formed by the outer edges of our domes and their host crater walls. These observations indicate to us that some craters on Ganymede have been partially filled with an endogenic (i.e., volcanic) extrusion. Based on the relative preservation of crater rimwalls in these craters and depths of fresh craters of similar sizes, we conclude that these extrusions could be up to 500 to $1000 \mathrm{~m}$ thick.

Similar crater floor domes have been subsequently recognized in lower resolution images of dark terrain in other areas, such as Nicholson and Barnard Regio, indicating they are global in extent. No crater floor domes occur within demonstrably young craters (those with bright rims or rays), or within craters on bright terrain. A search of stereo images of Callisto (over the $-20 \%$ of that surface that could be so observed) has not, with a few possible exceptions, revealed any floor domes similar to those on Ganymede [Schenk, this issue]. Crater floor domes therefore appear to be unique to the early pre-bright-terrain epoch on Ganymede.

\section{Crater Floor Domes-Enceladus}

The only landforms recognized on other icy satellites similar to the crater floor domes described above are located on

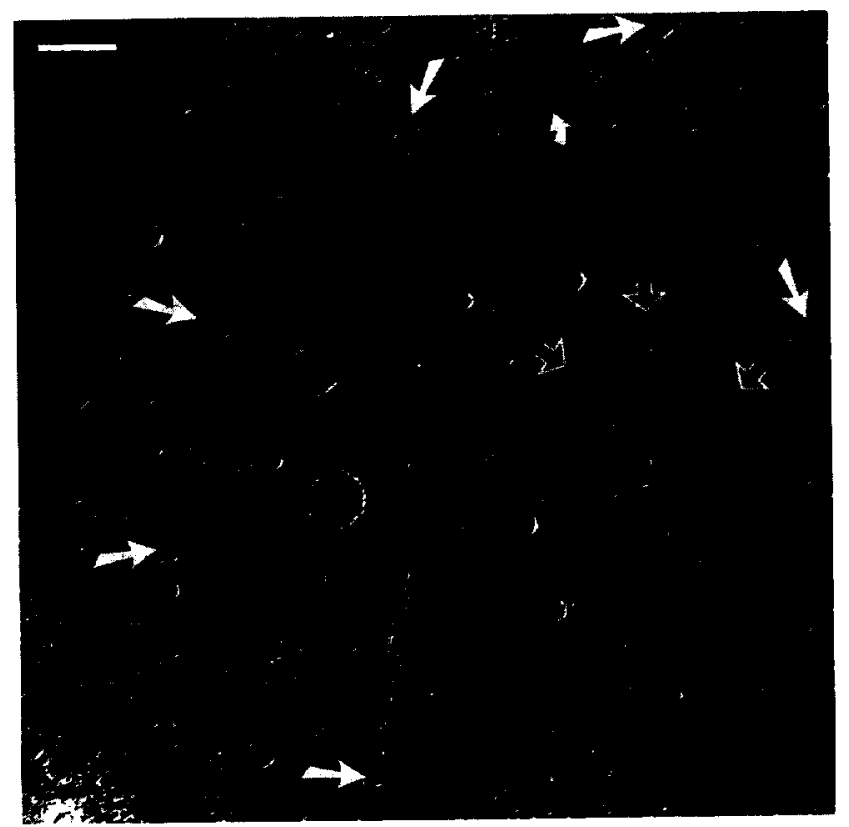

Figure 2. Voyager 2 image of a portion of Galileo Regio, Ganymede. A variety of volcanic features are evident in this section of ancient dark terrain. Numerous irregularly shaped crater floor domes are located on the floors of various craters (large arrows). Smooth dark material is also evident (open arrows). The northern half of Memphis Facula, a prominent palimpsest, is visible at lower right. (A throughgoing furrow is partially filled by a narrow ridge (small arrow), which might be volcanic or diapiric.) Voyager image 0455J2-001, centered on $24^{\circ} \mathrm{N}, 136^{\circ} \mathrm{W}$. North is up; scale bar is $75 \mathrm{~km}$ long. The stereo pair in Figure 1 is located in the upper right quadrant of this image. 


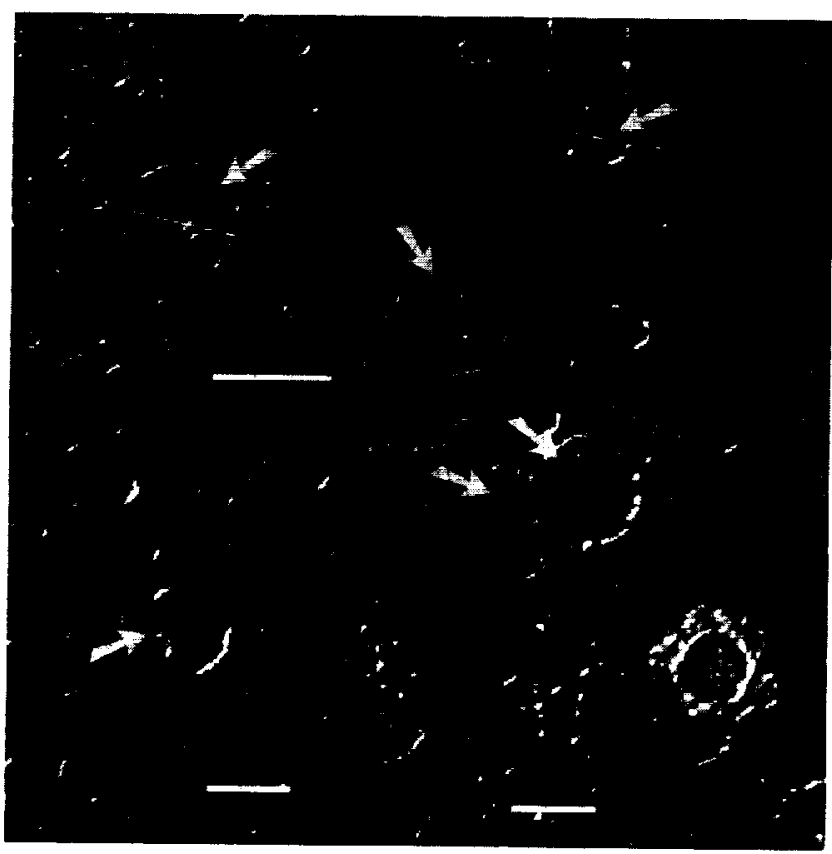

Figure 3. Close-up images of selected crater floor domes. The irregular shapes and margins of crater floor domes are evident. In several of these examples, large gaps can be seen between the dome and the crater rim. Two overlapping floor dome craters are seen at right center. Numerous scarps and possible flow fronts are also evident in the intercrater plains. Thin lines show locations of profiles in Figure 4 . Solar illumination is from the left in all cases. Images are portions of Voyager image 0455J2-001. Scale bars are $50 \mathrm{~km}$ long.

Enceladus. A comparison of craters of similar size on Mimas and Enceladus (Figure 5) reveals that many features described as central peaks on Enceladus are anomalous. Impact crater morphology is expected to be identical on these two satellites due to the nearly identical surface gravity [Schenk, 1989].

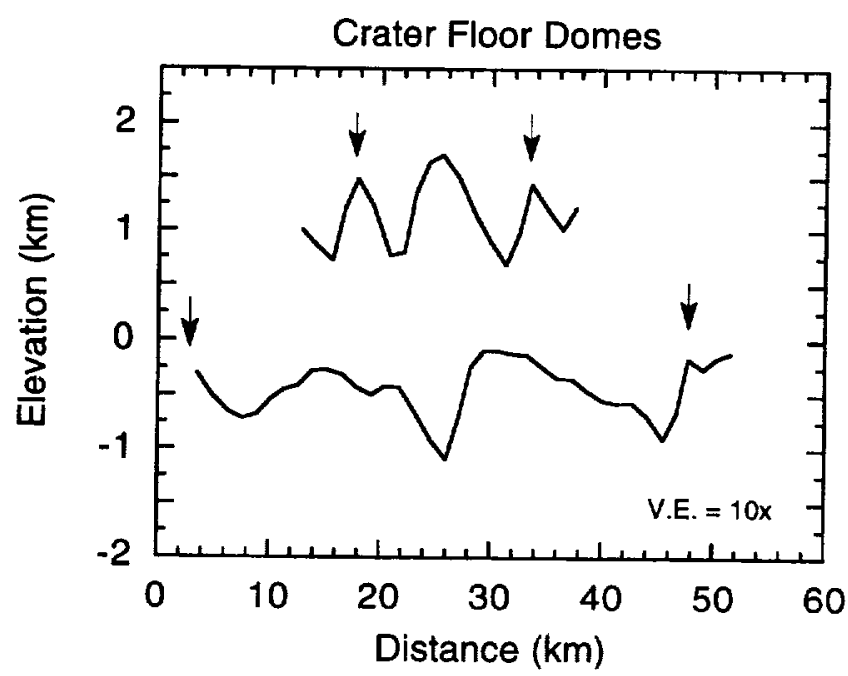

Figure 4. Topographic profiles across two craters with floor domes on Ganymede. Crater floor domes are evident in these profiles as the domical structure between the crater rims (arrows). The bottom profile was taken across the crater in the upper left corner of Figure 3. Profiles are from photoclinometry.

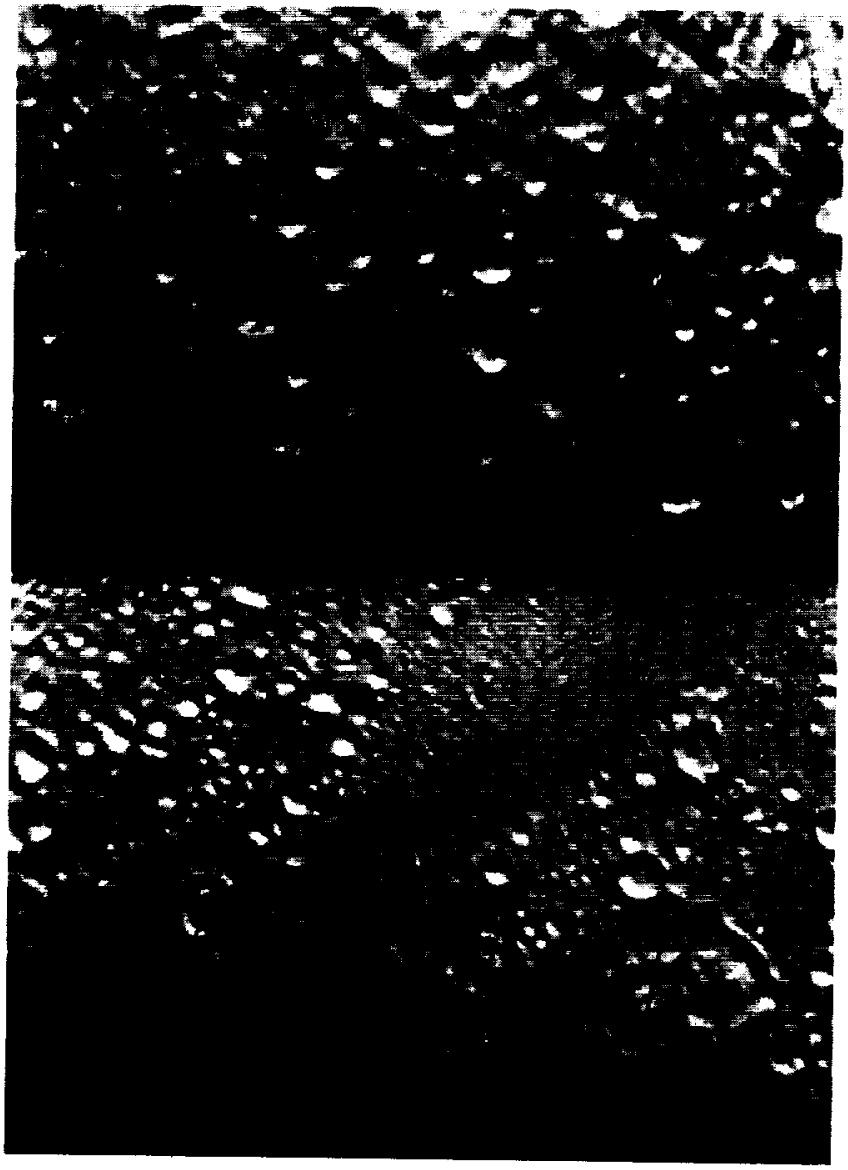

Figure 5a. Comparison of craters on Mimas (top) and Enceladus (bottom). These Voyager images were taken with very similar solar illumination and image resolution $(-800$ $\mathrm{m} / \mathrm{pixel}$ ). Images were projected into orthographic map format (accounting for ellipticity of some craters near the frame edges) and at the same scale to facilitate comparison. Despite nearly identical diameter, density, and surface gravity, there are pronounced differences in the occurrence of central structures and in their morphology on the two satellites (see text). Several of the anomalous domes on Enceladus, described in the text, are indicated (arrows). The central domes of craters Aladdin $(\mathrm{A})$ and $\mathrm{Ali}-\mathrm{B}$ aba $(\mathrm{AB})$ are particularly complex. Thin lines show locations of profiles in Figure 6 . Images $0025 \mathrm{~S} 1+000$ (top) and 1723S2-001 (bottom). Scale bar is 50 $\mathrm{km}$.

"Peaks" occur on Enceladus in craters smaller than $\sim 20 \mathrm{~km}$ across; craters of this size on Mimas are bowl-shaped and do not have central structures (Figure 5). More important, the shapes of the peaks on Enceladus are anomalous. Central peaks on Mimas and middle-sized icy satellites in general have a simple conical shape occupying about $1 / 3$ of the floor diameter [Schenk, 1989]. The crater floor domes on Enceladus, however, are often flat-topped and have steep outer slopes. Two domes also have small depressions at the top (Figure 5). In one case, the rim of a crater appears to have been breached (Figure 5b). Viscous relaxation models [Passey, 1983; Hillgren and Melosh, 1989] do not transform initially bowl-shaped profiles into central peaks or domes. Many of these domes may be volcanic, and probably have a similar origin to the crater floor domes on Ganymede. 


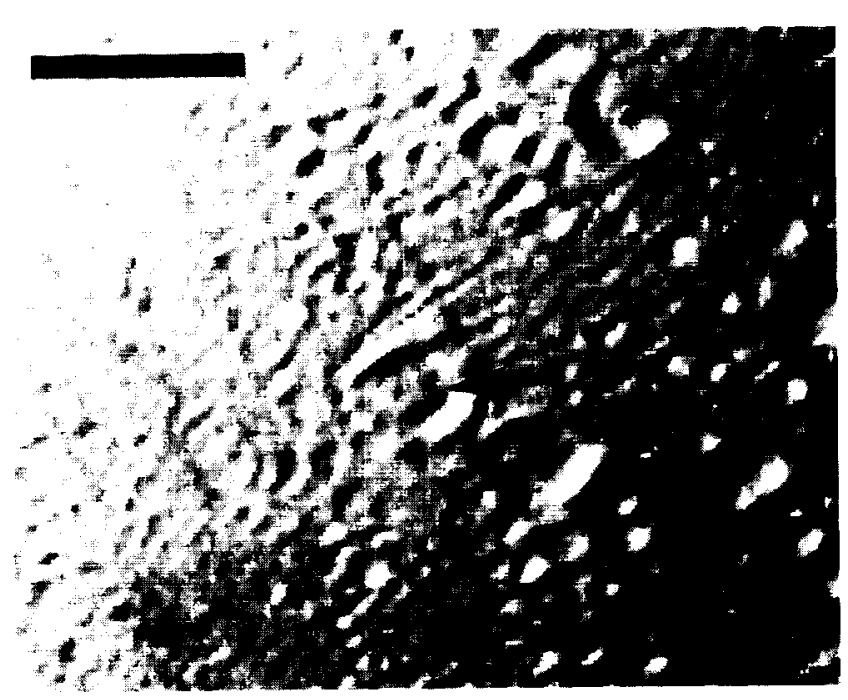

Figure 5b. Unrectified portion of image 1723S2-001, showing crater on Enceladus with irregularly shaped central dome material and breached wall (arrow). Material on the lefthand side is coarsely textured and devoid of craters. Material to the right of the breached crater appears to be moderately cratered smooth plains. This suggests that volcanic material from the left side of the image area embayed the breached crater. Scale bar is $50 \mathrm{~km}$.

Several domes have heights that equal or exceed the crater rim (Figure 6). These domes range from $<10$ to $20 \mathrm{~km}$ across and from $\sim 200$ to $1500 \mathrm{~m}$ in height (estimated photoclinometrically). The two largest craters, Ali-Baba and Aladdin, have complex central structures apparently constructed of multiple coalesced domes of various heights. The outline of the crater Ali-Baba (diameter $-35 \mathrm{~km}$ ) is also distinctly irregular, raising the possibility that some of these craterforms are partially or wholly endogenic in origin.

\section{Smooth Dark Deposits}

The geology of ancient dark terrains on Ganymede is complex and poorly understood. Smooth, dark, lightly cratered areas, forming irregular dispersed patches tens of $\mathrm{km}$ across, have been identified within dark terrain [e.g., Cassachia and Strom, 1984; Murchie et al., 1990]. Both groups hypothesize that these dark units are volcanic deposits, based on the smooth texture and low crater counts. Some of these units are visible in stereo images of Galileo Regio (Figure 1). These units often occur in shallow depressions that are sometimes scarp enclosed. In some areas dark smooth units appear to embay structurally deformed or eroded units in cratered terrain. Flow fronts were not detected, although some of the observed scarps may be flow fronts. Resolution is too poor to identify other structures or features associated with these deposits.

\section{Caldera-Like Structures}

Four of the sinuous semi-enclosed scarps described by Lucchitta as caldera-like were observed in the Voyager stereo coverage (Figures 7 and 8). These features consist of a single inward facing scarp, sinuous to scalloped in planform, forming a broad loop. The loop usually arcs back on itself but is always unclosed, the open end always abutting a swath or lane of bright material. They therefore appear to be "truncated," or "breached." In one case (Figure 7), a chain of irregular pits and depressions extends eastward from the main feature. Under high solar illumination, a bright annulus a few kilometers wide is seen extending outward from the scalloped scarp (Figure 9). These features are distinctly noncircular and lack a raised rim.
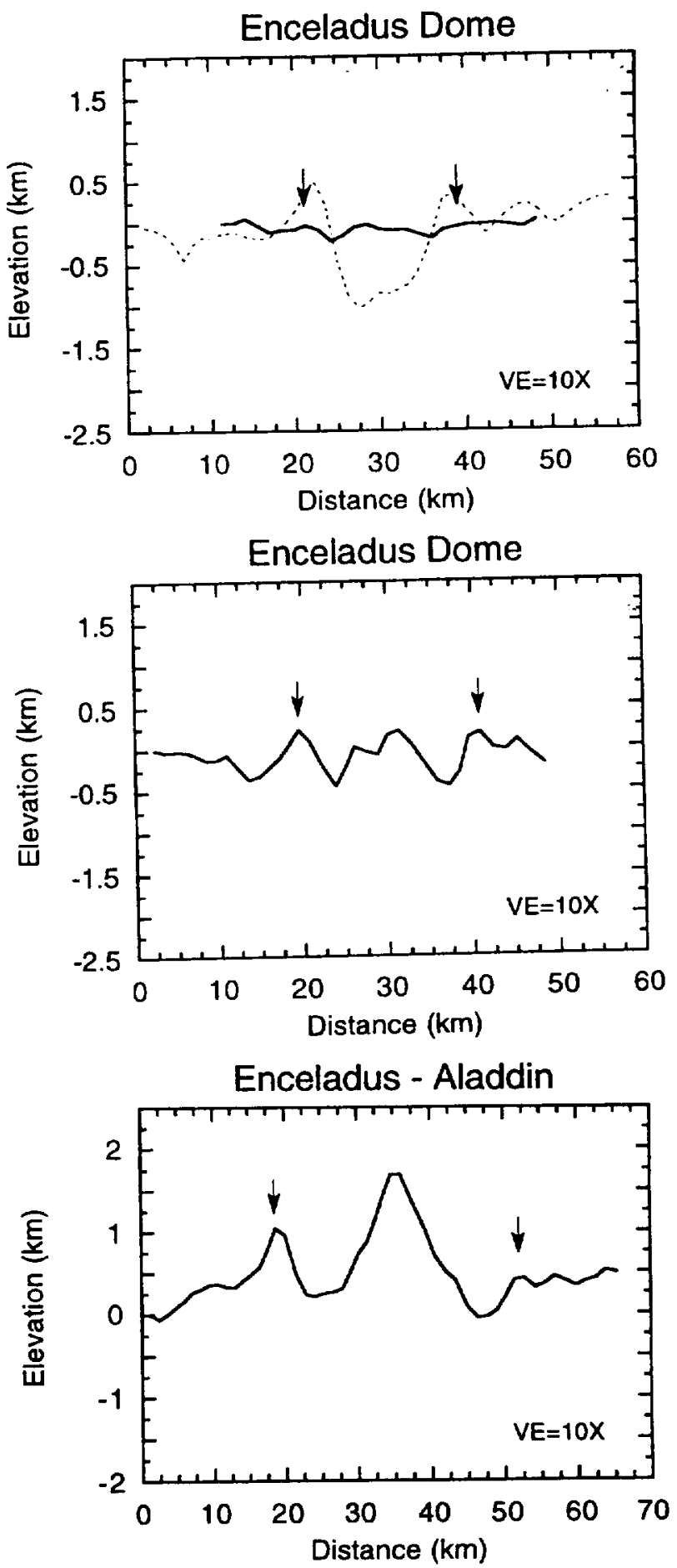

Figure 6. Topographic profiles across three craters with floor domes on Enceladus. Crater floor domes are evident in these profiles as the domical structure between the crater rims (arrows). The dashed profile in the top plot is a normal bowlshaped crater on Enceladus of similar size. Profiles are from photoclinometry. 


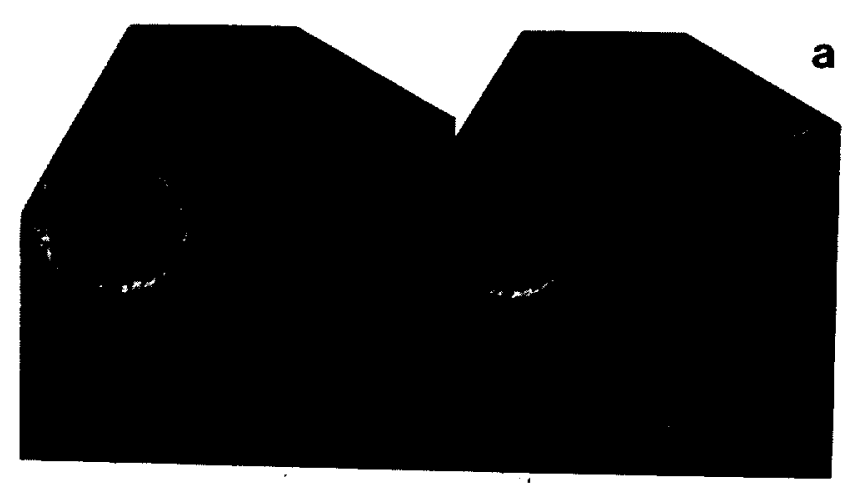

related to the formation of the caldera-like scarp. In one case, we estimate a minimum thickness for the smooth floor deposit, from photoclinometry, of $\sim 300 \mathrm{~m}$ (Figure 9).

We have identified at least 18 such structures (Table 1), including one that appears to crosscut an older example (Figure 10). As many as 22 of these structures may exist on Ganymede (Table 1; S. Murchie, personal communication, 1994). They are $25-80 \mathrm{~km}$ across in the long dimension. Two of the caldera-like features studied here (Figures 7 and 8 ) are truncated by the same lane of smooth terrain. Another cluster of eight caldera-like features (Figure 10, Table 1 [Lucchitta, 1980]) is
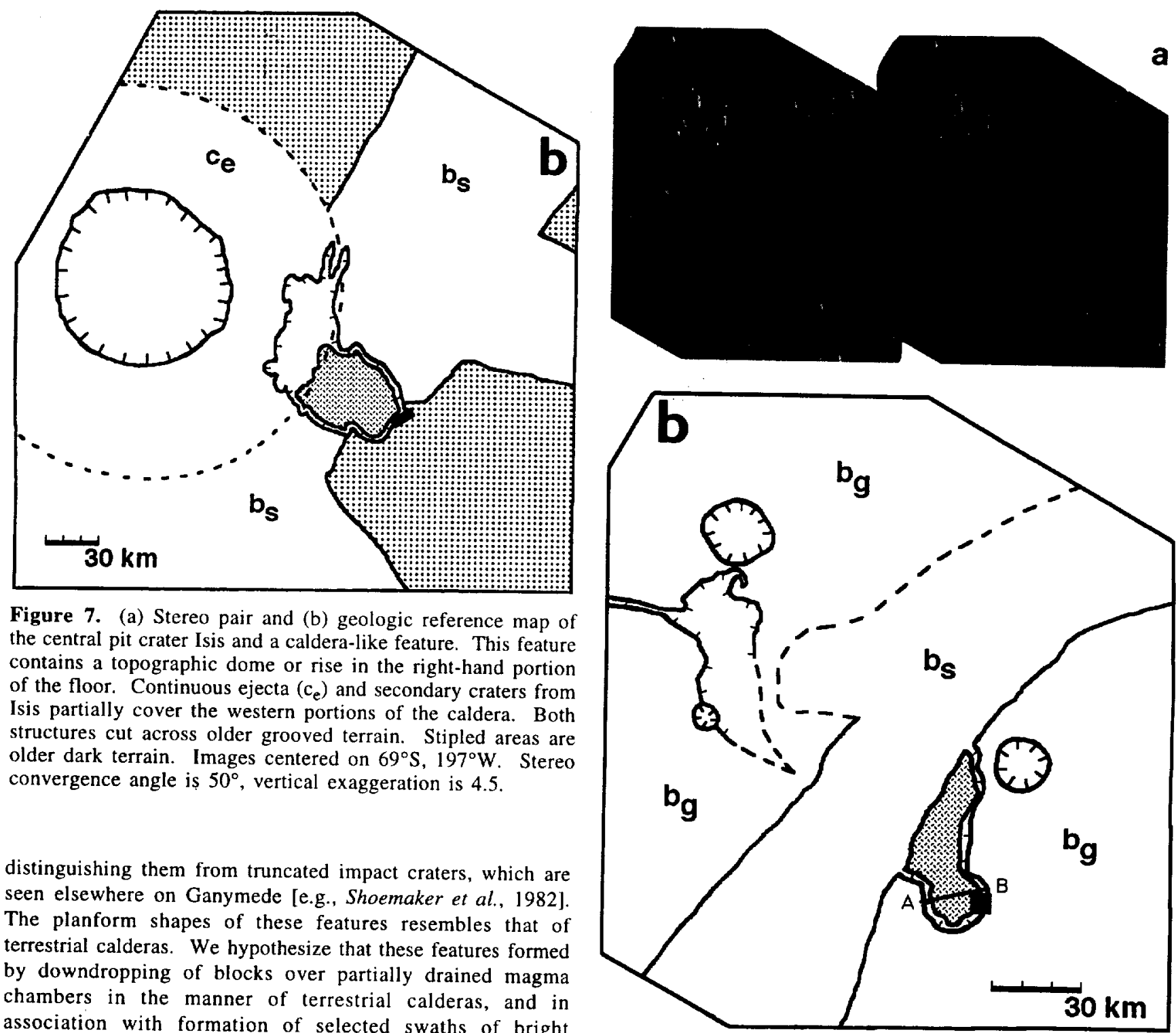

Figure 7. (a) Stereo pair and (b) geologic reference map of the central pit crater Isis and a caldera-like feature. This feature contains a topographic dome or rise in the right-hand portion of the floor. Continuous ejecta $\left(c_{e}\right)$ and secondary craters from Isis partially cover the western portions of the caldera. Both structures cut across older grooved terrain. Stipled areas are older dark terrain. Images centered on $69^{\circ} \mathrm{S}, 197^{\circ} \mathrm{W}$. Stereo convergence angle is $50^{\circ}$, vertical exaggeration is 4.5 .

distinguishing them from truncated impact craters, which are seen elsewhere on Ganymede [e.g., Shoemaker et al,, 1982]. The planform shapes of these features resembles that of terrestrial calderas. We hypothesize that these features formed by downdropping of blocks over partially drained magma chambers in the manner of terrestrial calderas, and in association with formation of selected swaths of bright terrain.

In three of the four structures we studied stereoscopically, the floor is filled with a texturally smooth deposit having a similar or higher albedo than the adjacent smooth terrain. This smooth material rises to an elevation similar to the surrounding terrain, and appears broadly domed (Figure 9). The floor material is typically bounded by a relatively steep outward facing slope, roughly matching the trace of the inward facing scarp described above. We interpret the smooth material as a resurfaced deposit, probably volcanic in origin,

Figure 8. (a) Stereo pair and (b) geologic sketch map of two caldera-like features near Bubastis Sulci, Ganymede. Both features cut across older grooved terrain and appear to be associated with the relatively young swath of smooth terrain $\left(b_{s}\right)$ in the center of the images. The caldera-like feature on the left side of the images is less well defined than the feature on the right. Images centered on $76^{\circ} \mathrm{S}, 161^{\circ} \mathrm{W}$. Stereo convergence angle is $45^{\circ}$, vertical exaggeration is 4 . The topographic profile in Figure 9 is indicated by the line A-B. Black square in Figure $8 \mathrm{~b}$ is a reseau located in the left-hand image. 


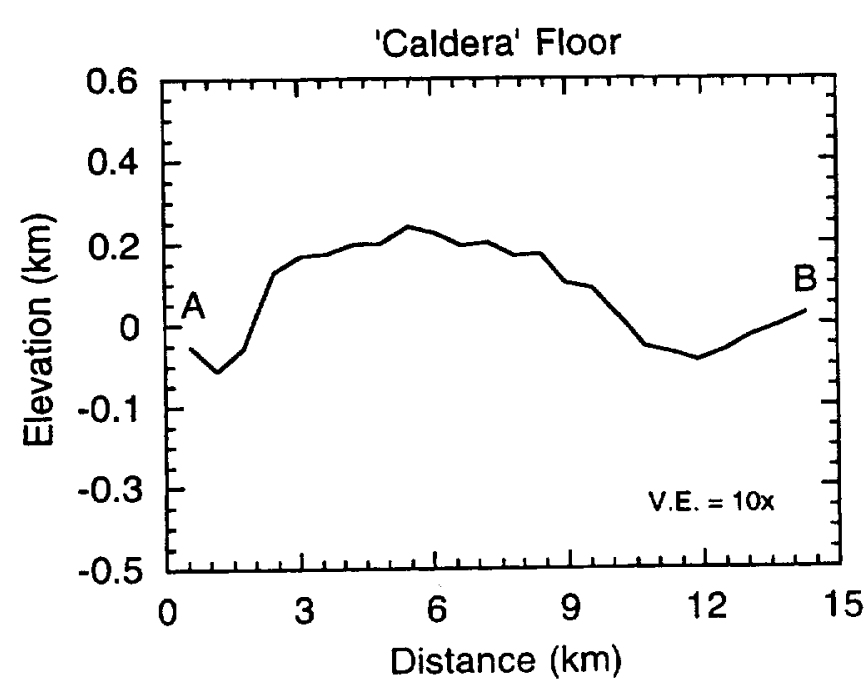

Figure 9. Topographic profiles across smooth floor of caldera-like feature in Figure 8a. Profile was not extended beyond the rim of the feature because of albedo changes. Profile is from photoclinometry.

located near $30^{\circ} \mathrm{S}, 183^{\circ} \mathrm{W}$ and appears to be associated with a particular swath of bright terrain. Otherwise, no particular concentration of these features was observed.

\section{Smooth Terrain}

Bright terrain is by far the most common endogenic resurfacing material on Ganymede, covering $50-60 \%$ of the surface. Bright terrain comes in two basic varieties, smooth bright material, and grooved (i.e., tectonized) bright material [Shoemaker et al., 1982]. Geological associations indicate

Table 1. Caldera-Like Features on Ganymede

\begin{tabular}{|c|c|c|c|}
\hline Latitude & Longitude & Dimensions, $\mathrm{km}$ & Image \\
\hline-46 & 141 & $80 \times 40$ & $0576 \mathbf{J} 2-001$ \\
\hline-18 & 211 & $80 \quad 10$ & $0401 \mathrm{~J} 2-001$ \\
\hline-68 & 204 & $70 \quad 50$ & $0530 J 2-001$ \\
\hline-32 & 187 & 70 & $0506 \mathrm{~J} 2-001 *$ \\
\hline-70 & 196 & 40 & $0666 \mathrm{~J} 2-001$ \\
\hline-77 & 163 & 60 & $0658 \mathrm{~J} 2-001$ \\
\hline-22 & 121 & 50 & $0558 \mathrm{~J} 2-001$ \\
\hline-30 & 183 & 50 & $0506 \mathrm{~J} 2-001^{*}$ \\
\hline-31 & 182 & 40 & $0506 \mathrm{~J} 2-001^{*}$ \\
\hline-32 & 182 & 40 & $0506 \mathrm{~J} 2-001^{*}$ \\
\hline 42 & 325 & 35 & $0859 \mathrm{~J} 1+000$ \\
\hline-28 & 174 & 30 & $0497 \mathrm{~J} 2-001 *$ \\
\hline-29 & 170 & 30 & $0497 \mathrm{~J} 2-001^{*}$ \\
\hline 1 & 325 & 20 & $0949 \mathrm{~J} 1+000$ \\
\hline-29 & 121 & 10 & $0566 \mathrm{~J} 2-001$ \\
\hline-19 & 144 & 25 & $0491 \mathrm{~J} 2-001$ \\
\hline-29 & 179 & 25 & $0506 \mathrm{~J} 2-001^{*}$ \\
\hline-30 & 179 & 25 & $0506 \mathrm{~J} 2-001^{*}$ \\
\hline 24 & 327 & 30 & $0967 \mathrm{Jl}+000^{\dagger}$ \\
\hline 66 & 11 & 40 & $0985 \mathrm{~J} l+000^{\dagger}$ \\
\hline-24 & 320 & 25 & $0941 \mathrm{~J} 1+000^{\dagger}$ \\
\hline-25 & 321 & 20 & $0941 \mathrm{~J} 1+000^{\dagger}$ \\
\hline
\end{tabular}

Locations from the Atlas of Jovian Satellites [Inge and Batson, 1992].

*These features are part of a cluster of eight similar features in Sippar Sulcus.

$\dagger$ Identification as caldera-like features is tentative

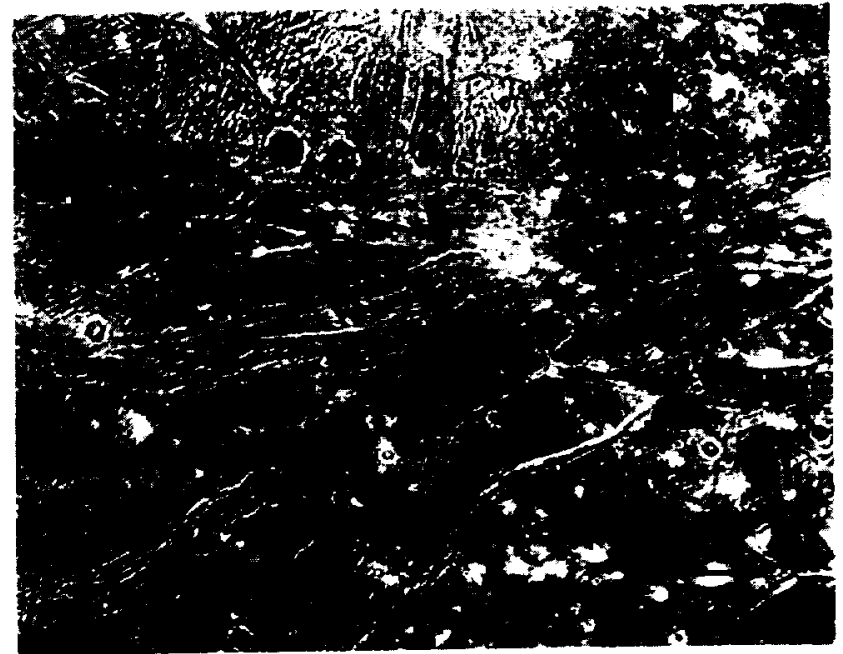

Figure 10. Voyager image of a cluster of six caldera-like features (arrows). At least five of these features abutt a through-going lane of smooth terrain extending diagonally across the scene. One of these features may crosscut an adjacent example (right center arrows). Two additional examples of this type of feature occur just off the upper right corner (Table 1). Portion of Voyager image 0506J2-001 is centered on $31^{\circ} \mathrm{S}, 183^{\circ} \mathrm{W}$. Scale bar is $200 \mathrm{~km}$.

bright material is relatively thin, $1-2 \mathrm{~km}$, and structurally confined within what are probably graben [e.g., Parmentier et al., 1983; Schenk and McKinnon, 1985]. Bright material may have been emplaced as either a fluid or in the solid state [e.g., McKinnon and Parmentier, 1986]. Unfortunately, no individual flow fronts can be identified with certainty in bright terrains (some bounding grooves that delineate sections of this terrain may be large-scale flow fronts, but resolution limitations do not allow us to evaluate this possibility). In a few localities, some bright material appears to have overflowed graben walls and formed deposits with possible topographic margins (for example, at $15^{\circ} \mathrm{S}, 151^{\circ} \mathrm{W}$, image 0485J2-001).

Prominent topography is evident within bright terrain, but is generally difficult to interprete. No flow fronts have as yet been identified. The best stereo coverage of Ganymede is centered on smooth and grooved terrains near the south pole, and we have searched these areas for topographic evidence of extrusion associated with bright terrain emplacement. An unusual exposure of bright terrain occurs at $77^{\circ} \mathrm{S}, 145^{\circ} \mathrm{W}$, in the form of a complex linear ridge at least $500 \mathrm{~km}$ long flanked on either side by smooth material extending laterally for distances of up to $50 \mathrm{~km}$ (Figure 11). The smooth material and ridge cut across Bubastis Sulci, a major groove packet at least $500 \mathrm{~km}$ wide (it is the only structure cutting Bubastis). This exposure is unusual in that it is one of the few sites where smooth terrain is not structurally confined by scarps or lineaments.

Topographically, this smooth deposit and ridge lie in a shallow, broadly downwarped depression crossing Bubastis Sulci. The ridge itself consists of several discontinuous segments, which, uncharacteristically for Ganymede, vary substantially in height and width along their length (Figure 11). The northern termination of this ridge is indistinct and gradually tapers out within an area of smooth deposits. The 


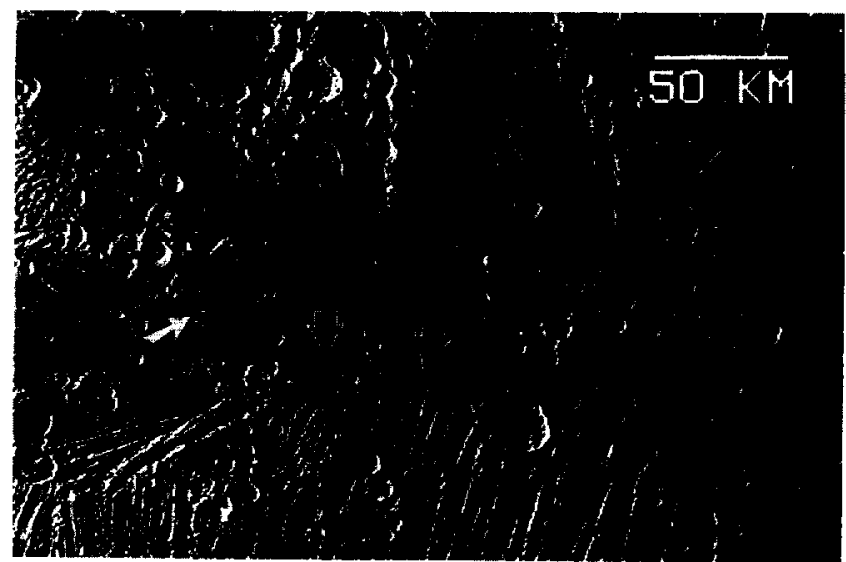

Figure 11a. Voyager image of smooth terrain within Bubastis Sulci, Ganymede. Smooth bright material (open arrows) clearly embays ridges within Bubastis Sulci (parallel ridges and troughs extending through right half of image). Parallel discontinuous ridges (solid arrow) appear to be embayed by smooth material as well. The large complex through-going ridge discussed in the text crosses the image diagonally from left to lower right. Irregular craters and crater chains are secondaries from the Gilgamesh multiring structure located due north of this scene (north is to the top). Image centered on $77^{\circ} \mathrm{S}, 140^{\circ} \mathrm{W}$. Image resolution $\sim 500 \mathrm{~m} /$ pixel. Image 0670J2-001.

ridge doubles in places, which along with its linearity indicates an underlying structural control of its emplacement.

The contact between the smooth deposits and grooved terrain closely follows topographic contours. Smooth material clearly embays grooves of Bubastis Sulci (Figure 11b) in the same way that lunar mare embay craters, and is hence younger. The smooth deposit cannot be thicker than $-300 \mathrm{~m}$ at its edge and remain undetectable (for this stereo geometry). We believe it is probably much thinner at the margin than 300 $\mathrm{m}$ (and probably less than $50 \mathrm{~m}$ ) based on the clear embayment relationships and the lack of topographic brightening or shading along the edge, especially given the favorable

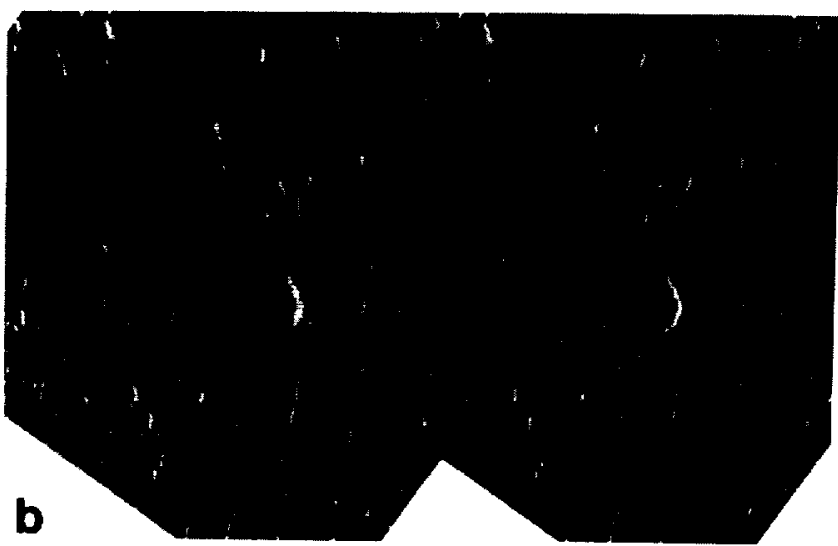

Figure 11b. Stereo images of smooth bright terrain (from Figure 11a), illustrating the completeness (to the resolution limit) of the embayment relationship between smooth terrain and grooved terrain in this area. The complex ridge running through the smooth material is also seen. North is up. Stereo convergence angle is $59^{\circ}$, vertical exaggeration is 6 .

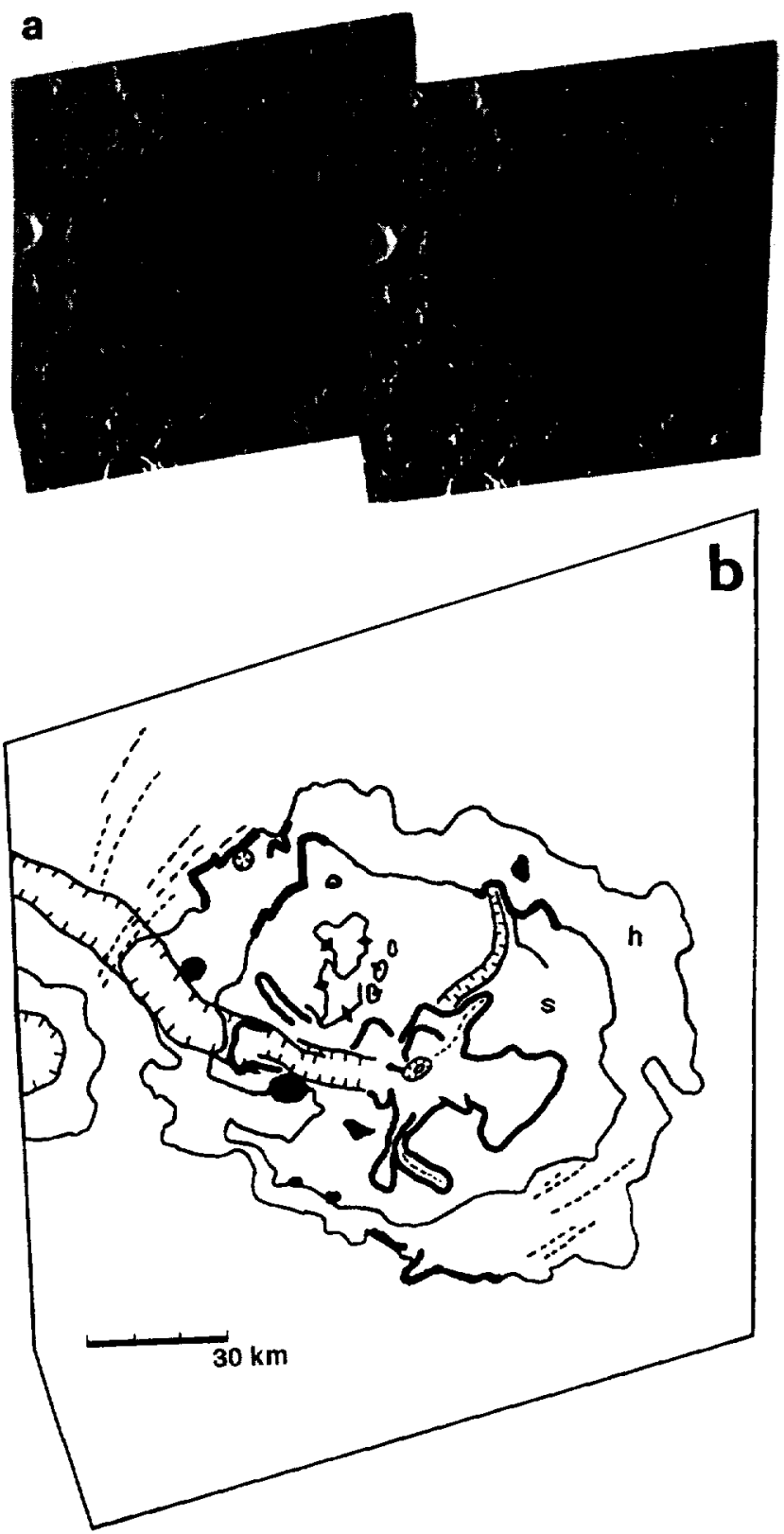

Figure 12. (a) Stereo pair and (b) geologic reference map of the smooth material in the central floor of the Gilgamesh multiring structure, Ganymede. The outer boundary corresponds to the outer edge of a hummocky unit (h), inferred to be a possible impact melt deposit. The inner boundary corresponds to the outer edge of the smooth floor deposits (s). Lobate textures, highlighted by thick lines, are inferred by us to be possible flow margins (or features due to deformation). Two linear troughlike features, inferred to be grabens, are also visible (parallel lines with hash marks). Isolated peaks within the smooth material may be remnants of a possible buried inner ring. Dashed lines are faults or scarps. Images centered on $62^{\circ} \mathrm{S}, 123^{\circ} \mathrm{W}$. Stereo convergence angle is $17^{\circ}$, vertical exaggeration is 2 .

lighting in this region. In addition, a number of parallel discontinuous ridges are seen isolated within this patch of smooth terrain (Figure 11). These ridge segments all appear to be partially flooded remnants of ridge and trough terrain. These observations are consistent with the extrusion of a fluidlike material for the origin of these smooth deposits. 


\section{The Floor of Gilgamesh}

An extensive and generally smooth deposit occurs in the central floor of Gilgamesh (diameter $\sim 550 \mathrm{~km}$ ), the largest well-preserved multiring impact structure on Ganymede. The central floor is $-110 \mathrm{~km}$ in diameter. Stereo images (Figure 12) of the central floor of Gilgamesh reveal that it is domed upward 2 to $2.5 \mathrm{~km}$ (measured photogrammetrically, Figure 13) relative to the margin. The topographic doming is asymmetric and centered in the eastern portion of the floor.

At several locations, the edge of the smooth deposit has a topographic step and lobate outline (Figure 12b), suggesting flow. The maximum thickness of individual lobate features at

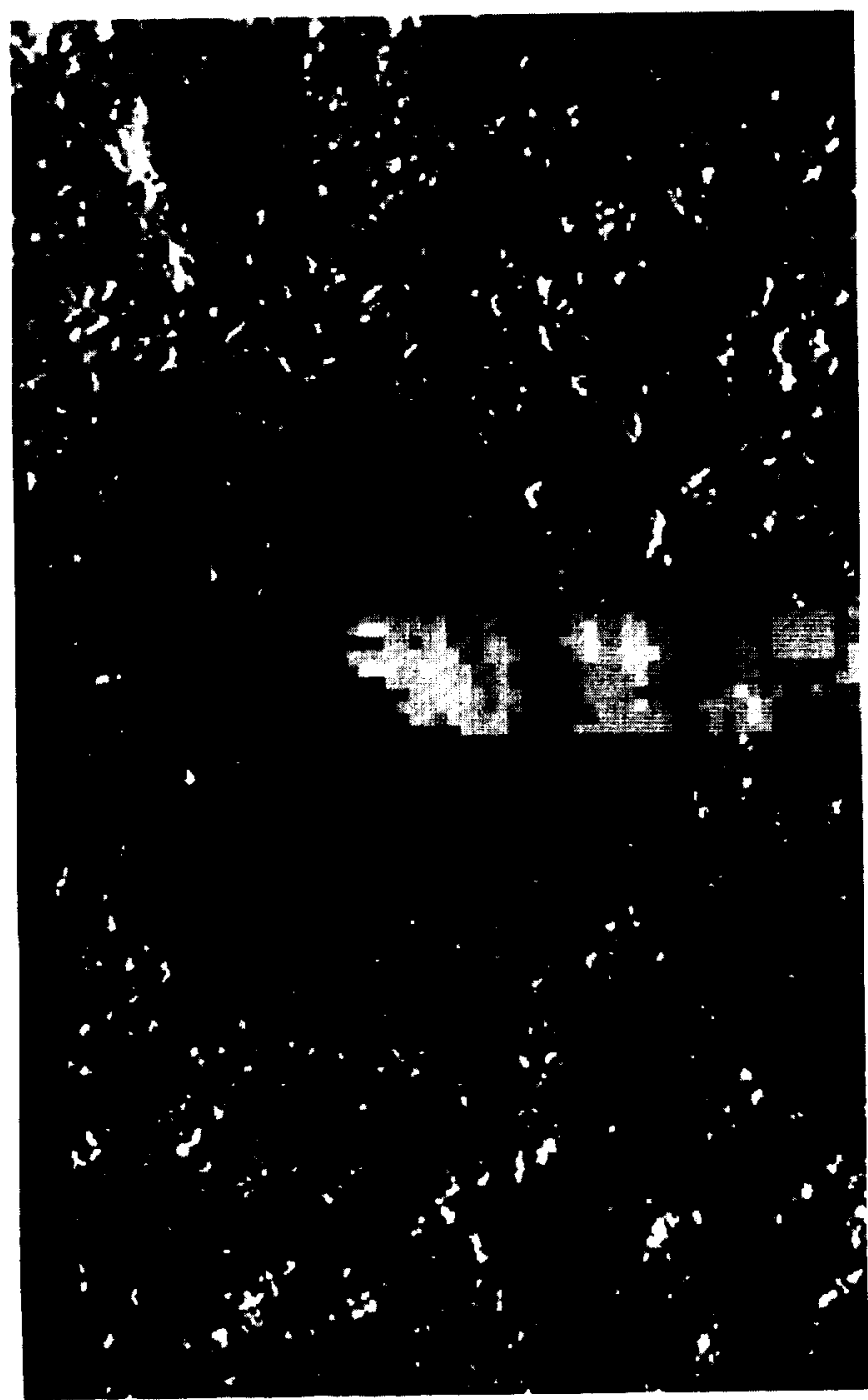

Figure 13. Central floor of Gilgamesh, with digital elevation model (DEM) superimposed (swath of coarse gray pixels across center of image). Bright pixels represent high elevation, dark pixels low elevation. DEM data confirm the impression from the stereo pair in Figure 12 that the floor of Gilgamesh is domed upward 1-2 km, and that the doming is asymmetrically displaced toward the eastern half of the basin floor. Total relief across the dome feature is $\sim 2.5 \mathrm{~km}$. DEM data were produced from an automated stereo photogrammetry routine developed at the lunar and Planetary Institute. Stereo matching was done every 10 th pixel and averaged to fill in unsampled areas. Voyager image 0590J2-001. the margin is estimated (photoclinometrically) to be $\sim 150 \mathrm{~m}$. A number of subtle sinuous and Iobate features are also observed within the smooth material (Figure 12). These features have very low relief of probably less than $50 \mathrm{~m}$, based on comparison with the lobate features at the margin. A $5-\mathrm{km}$ wide elliptical feature is also located near the center of the smooth floor deposit (Figure 12). A 10-km-wide grabenlike depression extends from the middle of the central floor westward into the surrounding zone of massifs. A similar trough extends from the center to the northeast. The Gilgamesh basin and its ejecta are superposed on both dark and bright terrains in this region. Hence, if the smooth deposits on its floor are volcanic materials, then they are among the youngest on Ganymede.

\section{Origins of Volcanic Deposits on Ganymede}

Volcanic materials on Ganymede and other icy bodies are difficult to characterize, given the lack of compositional constraints. We are limited in our understanding of the "volcanic" behavior of ices, and must proceed, despite possible exotic processes involved in icy volcanism, dependent in large part on terrestrial analogs. We describe here possible and preferred scenarios for the formation of different styles of volcanic constructs that can be tested with new data from the Galileo Orbiter beginning in mid- 1996.

\section{Volcanic Deposits Without Apparent Topography}

Smooth dark deposits and their associated depressions, such as within Galileo and Marius Regios, are the most cryptic of Ganymede's endogenic units. The smoothness and lack of craters on these deposits could be consistent with volcanic resurfacing [Murchie et al., 1990]. If volcanic, the low albedo would suggest that their composition is distinct from the other volcanic units described here. Murchie and Head [1988] suggest they could be composed of ammonia-water, subsequently darkened by devolatilization. Interestingly, the only evidence for ammonia among the Galitean satellites is the tentative identification of ammoniated clays on Callisto and not on Ganymede [Calvin and Clark, 1993]. The low stereo relief indicates these deposits may be much thinner than the 300-800 m suggested by Murchie et al. [1990].

Conversely, the smooth dark material may be erosional debris formed by sublimation-induced scarp retreat within dark terrain, as hypothesized by Moore and Zent [1994]. Erosional landforms of this type are observed near the south pole of Mars [Sharp, 1973a, b]. A residual dark deposit is what would be expected from volatile sublimation of a dirty water-ice surface, leading to scarp retreat [Moore and Zent, 1994]. High-resolution ( $<200 \mathrm{~m} / \mathrm{pixel})$ low-Sun images of the contact are needed to determine whether dark smooth material lies at the base of a retreating scarp or alternatively volcanically embays low-lying topography.

Bright terrains, on the other hand, are almost certainly extrusive. Bright terrain moprhology is variable and may have been extruded under a range of conditions. The embayment of smooth material into grooves in adjacent terrains and the lack of topographic relief at the site near the south pole (Figure 11) is a clear indication of flow of very low viscosity material into topographic depressions. This is the best available evidence for emplacement of volcanic liquids on Ganymede in at least one locality. Whether produced during 
one massive outflow or as a sequence of thin flood lavas is presently impossible to determine. We cannot, however, extrapolate this conclusion to other exposures of bright terrain.

The complex morphology of the medial ridge associated with the south pole smooth deposits (Figure 11) suggests that it could be a volcanic ridge and may have shared the source of the smooth materials. Symmetric, continuous, and sharply defined ridges (and troughs) which make up grooved terrain within Bubastis Sulci are generally believed to be formed from extensional tectonics [Squyres, 1981; Shoemaker et al., 1982]. The irregular, discontinuous morphology of the transverse ridge, and its association with the locallized emplacement of smooth material to either side could imply a different or more complex origin for that feature. Probable volcanic ridges have been reported on Miranda and Ariel [Jankowski and Squyres, 1988; Schenk, 1991a; Greenberg et al., 1991; Croft and Soderblom, 1991], and fissure eruptions are common in Hawaii and Iceland. We speculate that the smooth deposits originated from a fissure vent, located at the present site of the ridge and perhaps analogous to the features inferred to be volcanic ridge extrusions on Ariel and Miranda. The ridge could represent a late stage in the extrusion sequence when flow viscosity increased, either due to partial crystallization and/or cooling of the magmas. We concur with the supposition of Shoemaker et al. [1982] that some of the other solitary ridges that occur within bright terrain on Ganymede could be volcanic structures as well. Tests for various ridge forming processes are discussed by Pappalardo and Greeley [1995], which can be applied to solitary ridges imaged by Galileo.

The other possible site for areally extensive volcanic deposits is in the center of Gilgamesh, for which we consider two possible interpretations. The first is the Mare Orientale analogy, in which the floor of Gilgamesh has been partially filled with a succession of overlapping thin flows, emanating from the central area. The result might be the construction of a broad shieldlike volcanic construct. A genetic relationship between the lobate and elliptical features and the grabenlike structure on the floor of Gilgamesh is suggestive but difficult to unambiguously evaluate. The palimpsest formation model of Thomas and Squyres [1990] might be generally applicable to this interpretation.

The second interpretation of the central floor material of Gilgamesh is that it is essentially an extremely large variant of a central pit dome [see Moore and Malin, 1988; Schenk, 1993]. Pit domes partially fill central pits in regular craters, and appear to have an intrusive morphology. The smooth domed material would be analogous to the central pit dome, and the ring of massifs surrounding the deposit would be analogous to the central pit wall. Numerous sinuous and elliptical features are seen on the central floor of Gilgamesh. Sinuous structures formed by folding and faulting occur extensively in both diapirs and uplifted central peaks on Earth [e.g., Wilshire et al., 1972; Milton et al., 1972; Jackson et al., 1990]. Both diapirism [Moore and Malin, 1988] and uplift during impact [Schenk, 1993] have been proposed to explain central pit dome formation. For Gilgamesh, the smooth central floor would be exposed deep-lying lower-viscosity material, intensely deformed during central uplift of the crater floor or by solid-state effusion soon after impact. Unfortunately, Galileo will not image Gilgamesh, and we will have to address these issues indirectly by examination of other large impact structures.

\section{Volcanic Constructs}

A principal finding of our research is the first evidence for relatively thick (>100 m) volcanic constructs on Ganymede. These occur in two (or possibly three) type localities: crater floor domes (on both Ganymede and Enceladus), the floors of caldera-like structures, and perhaps as individual ridge structures within bright terrain.

Crater floor domes (Figures 1 and 2) have not been previously recognized on Ganymede. As described earlier, the topography of floor domes appears to be inconsistent with that expected from viscous relaxation. Other morphologic aspects lead us to propose that crater floor domes are volcanic in origin. Landforms produced by low-viscosity lavas do not generally produce flows with thick steep-sided margins, but rather produce large shieldlike structures or flood plains where flows usually fill and embay topographic depressions. Steepsided domes tend to be produced by intermediate- and highviscosity lavas. Steep-sided domes can be formed by a pulsed series of low volume, low viscosity extrusions [Fink et al., 1993], but such probably require specific environmental (e.g., subaqueous) conditions unusual for Ganymede. The general correlation of volcanic composition with flow morphology suggests to us that crater floor domes may have formed during a continuous (though not necessarily steady) extrusion of relatively more viscous material.

Crater floor domes are distinct from bright pit domes, found within central pits of craters larger than $-60 \mathrm{~km}$ on both Ganymede and Callisto [Moore and Malin, 1988; Schenk, 1993]. Floor domes are not restricted to the central uplift complex, but extend over large parts of the crater floor. Also, pit domes occur in craters on all terrain types and ages, which is not true of crater floor domes. It has been argued previously [Schenk, 1993] that the ubiquity of pit domes in large craters indicates they are related to the cratering process. The presence of floor domes only in some older craters of various sizes is probably more consistent with an endogenic process such as volcanism, which presumably would have been more pervasive in early ganymedean history. High-resolution, lowSun Galileo images could reveal the presence or absence of process-diagnostic flow textures on floor domes.

The morphology and topography of domelike features in many craters on Enceladus suggests they formed in a manner similar to crater floor domes on Ganymede: by extrusion of volcanic material into the crater floor. A composition-related impact origin for the anomalous central peaks on Enceladus is possible, but no mechanism is obvious. While an ammoniawater-ice crustal composition (as suggested by Passey [1983]) might conceivably account for the variation in transition diameter between Mimas and Enceladus, there is no obvious reason to believe that distinctly different shapes should result from impact into different ices. One of the craters with a central dome appears to be breached by smooth material (Figure 5b), possibly from outside the crater. These domes may be related in some way to the low-relief smooth material, inferred to be volcanic, observed over much of Enceladus [Smith et al., 1982]. Volcanism on Enceladus may have been complex and may have varied with location and time.

It is conceivable that the craters on Enceladus in which these domes occur could themselves be volcanic explosion 
craters, as suggested by the non-circularity of some craters. Alternatively, the crater shapes could be the result of surrounding material being uplifted by the emplacement of the domes. The anticipated Cassini images of Enceladus should answer many of these questions.

The irregular scalloped scarps referred to as caldera-like by Lucchitta are the only candidate volcanic caldera structures identified on Ganymede. The morphology of these landforms also resembles that of an $80-\mathrm{km}$-wide enclosed depression on Triton, generally interpreted as a volcanic caldera [Croft et al., 1995]. This feature on Triton has a sinuous to scalloped rim, and several domed floor deposits. It is reminiscent of terrestrial calderas, such as Valles Caldera, in that it appears to be partially flooded by late stage viscous extrusions and modified by resurgent doming. The Triton "caldera" is associated with a very extensive zone of resurfaced material that is not structurally confined. In contrast, resurfacing associated with the caldera-like features on Ganymede is limited to smooth bright materials that fill the floor, and swaths of bright terrain that abutt the caldera-like features. It is not clear whether the smooth floor deposit originated from floor fractures or flowed in through the gaps in the rims. In any case, the caldera-like features appear to be associated in some way with the later period of bright terrain formation, and represent an unusual phase in Ganymede volcanism.

Terrestrial calderas can be sites of explosive (i.e., gascharged) or effusive volcanism, or both. Unlike many terrestrial and Martian examples (such as the summit calderas of Mauna Loa or Olympus Mons), the Ganymede features are not associated with large shields, radial flow complexes, or topographic rises. We find no evidence for associated pyroclastic deposits or external deformation, regional uplift or volcanic construction. Galileo is targeted to image at high resolution several of these caldera-like features. Detailed study of deposits associated with these features and their contacts with one another should clarify the character of this relatively recent volcanic activity on Ganymede.

\section{Ruminations on Rheology}

In the absence of disk-resolved spectra capable of resolving geologic units, we can only speculate on the composition of lava flows on Ganymede. The long-surviving high albedo of bright terrain and strong water ice absorptions on Ganymede in general are relatively good indicators that $\mathrm{H}_{2} \mathrm{O}$ is a major constituent of bright terrain (and perhaps other units) [e.g., Allison and Clifford, 1987]. We are, at present, limited to remote sensing of flow dimensions in order to constrain flow rheology.

The problems associated with determining flow rheology, as applied to icy planetary surfaces, have been discussed [e.g. Jankowski and Squyres, 1988; Melosh and Janes, 1989; Schenk, 1991a]. For the sake of comparative study of volcanic deposits on other icy satellites (e.g., Miranda, Enceladus, and Ariel), we employ the technique of Schenk [1991a], emphasizing that rheologic estimates can be uncertain by several orders of magnitude. Nevertheless, they can provide some constraints on eruption conditions and may help eliminate some candidate materials.

Lava flows can be modeled as Bingham fluids, which is an approximation of the more realistic viscoplastic rheology (see review by Chester et al. [1985]). These materials will flow with a viscosity, $\eta$, as long as the bulk yield strength $\left(\tau_{0}\right)$ is exceeded. Yield strength can be estimated from the shape the flow assumed when it ceased movement [Blake, 1990], where $\tau_{0}=\rho h^{2} g / 3 r$, where $h$ and $r$ are the height and radius of the flow. An estimate of flow viscosity ([Huppert et al., 1982]: see (1) of Schenk [1991a]) requires an estimate of the duration of flow, which can only be deduced theoretically. Following Schenk [1991a], we use the characteristic cooling time of Crisp and Baloga [1990], which appears to approximate the known cooling and solidification times of terrestrial volcanic flows better than the diffusion cooling time. We could also use the Graetz number, which is $-1 / 300$ th the diffusion timescale [Hulme and Fielder, 1977], and produces similar results as the characteristic cooling time. However, there is little hope of ever knowing flow emplacement times on icy satellites without field mapping and sampling. An additional problem is that most volcanic flows develop a rigid outer crust that is not accounted for in the isothermal Huppert et al. model. Viscosities derived from this model overestimate measured viscosities of actual flows by 3-5 orders of magnitude [e.g., Huppert et al., 1982; Murase et al., 1985]. For this reason. Schenk [1991a] and Greenberg et al. [1991] assumed a 4order-of-magnitude correction to derive an approximate extrusion viscosity, and we follow this practice for consistency.

\section{Flow Viscosity Estimates}

The thinnest observed volcanic units on Ganymede, the smooth deposits near the south pole (Figure 11), are also probably the least viscous. Without individual lava flows to measure, we can only obtain an approximate upper limit on viscosity, based on our maximum thickness at the margins of this unit $(-50 \mathrm{~m})$. This is very approximately $<10^{3} \mathrm{~Pa} \mathrm{~s}$, with yield strengths of $<0.1 \mathrm{kPa}$. Certainly fluid water-dominated lavas are plausible, if not likely, based on these rheologic limits and spectroscopic evidence for abundant water ice on Ganymede.

For the Gilgamesh floor deposits, we use the dimensions of the thickest apparent flowlike features along the margin, which are $-150 \mathrm{~m}$ thick and $\sim 10 \mathrm{~km}$ across, as an upper limit. From this we estimate that the smooth materials have viscosities of $\sim 10^{6} \mathrm{~Pa}$ s or less, and yield strengths of $0.2 \mathrm{kPa}$ or less. (Unresolved thin flows, if they exist, would have considerably lower viscosities.) These values are comparable to or weaker than the estimated rheologies of ridge flows on Miranda $-500 \mathrm{~m}$ high (where $g$ is $<0.1$ that of Ganymede). They could be consistent with either the "Mare Orientale" or pit dome interpretation for the construction of the Gilgamesh floor deposits, depending on extrusion conditions. Warm material exposed from depth could flow, deforming plastically, with these viscosities and yield strengths. Alternatively, a partially crystalline melt could easily be extruded, although it is doubtful a pure water melt could achieve topography anywhere close to $150 \mathrm{~m}$ of topography at the flow margin, because of its extremely low viscosity. If the extrusion was a liquid, then a fluid with higher effective viscosity is implied.

We do not know the source of the smooth material on the floors of the caldera-like features. If we assume these materials were extruded from the floors of these features as a more-or-less continuous extrusions and have thicknesses of $\sim 300 \mathrm{~m}$ (Figure 9), we obtain viscosities of $-10^{10} \mathrm{~Pa} \mathrm{~s}$, and yield strengths of 
$\sim 10 \mathrm{kPa}$. Crater floor domes were most likely extruded from within the crater floor. The estimated viscosities of crater floor domes (with maximum thicknesses of 500 to $1000 \mathrm{~m}$ ) range from $10^{8}$ to $10^{10} \mathrm{~Pa}$ s. Yield strengths range from approximately 1 to $100 \mathrm{kPa}$. These are the highest viscosities and yield strengths estimated for materials on Ganymede, and are comparable to or stiffer than the estimated rheologies of volcanic ridges on Ariel and Miranda. Ridge material, if it is volcanic, probably has even higher viscosities, based on their heights of 500 to $1000 \mathrm{~m}$. The estimated viscosity of the domes on Enceladus range from $10^{6}$ to $10^{8} \mathrm{~Pa} \mathrm{~s}$, with yield strengths of $\sim 1$ to $10 \mathrm{kPa}$. This is only somewhat weaker than for the Ganymede domes.

\section{Speculations and Conclusions}

Perhaps the most interesting and unexpected conclusion suggested by our topographic analysis of Ganymede's surface is the evidence for the extrusion of relatively viscous materials on Ganymede. Most observers have concluded that the younger bright terrain which covers half of the surface was emplaced by a very low viscosity material, hence the lack of discernable relief. Extrusion of both low- and high-viscosity materials indicates that the petrology of Ganymede's magmas could be more complex than simply that dominated by $\mathrm{H}_{2} \mathrm{O}$ ice. This would be consistent with the speculation of Murchie and Head [1990] that ammonia-rich fluids may have been involved in forming smooth, dark (and thin) deposits in dark terrain (although their compositional inference was based solely on the low albedo and is presently without topographic or spectroscopic corroboration).

Despite pre-Galileo limitations, we propose a preliminary, although testable, scenario for the formation of volcanic units on Ganymede. The earliest volcanic materials appear to be dark smooth deposits in dark terrain [Casacchia and Strom, 1984; Murchie et al., 1990]. These deposits are thin and possibly had low viscosities. Some scarps associated with these deposits could be flow fronts. In any case, the dark deposits are difficult to characterize beyond these tentative speculations. The crater floor domes found in some older craters on dark terrain may have formed concurrently or soon after the emplacement of dark deposits. Dome materials may have been relatively viscous, but were not very voluminous. These domes predate bright terrain material. Crater floor domes appear to be present on Enceladus.

These early events within dark terrain were followed by the prolonged episode of bright terrain emplacement. The youngest bright terrain deposits often appear smooth and untectonized. Stereo imaging confirms that some of these deposits have no discernable relief and may constitute some of the least viscous materials extruded on Ganymede. The later stages of bright terrain formation were punctuated by the formation of a number of caldera-like features, which may indicate the formation of isolated shallow magma chambers. Materials covering the floors of these features may have been moderately viscous. Materials with relatively low to intermediate viscosities were emplaced on the floor of the Gilgamesh impact basin, either as viscous extrusions or as solid-state flows. The bright material comprising large palimpsests (e.g., Figure 2) could also be included in this volcanic group. Palimpsest deposits have been interpreted as volcanic material extruded shortly after or during impact into an ancient, rheologically soft "mantle" [Thomas and Squyres, 1990].
Our morphologic studies of volcanic constructs on Ganymede imply that the extrusion viscosities of these materials vary over at least 7 orders of magnitude, and yield strengths by over 3 orders of magnitude (Figure 14). Compositions of these volcanic materials are currently unknown, but this range of rheologic properties indicates that materials of different compositions or different amounts of mixed crystals may be involved.

The viscosity of pure water ice at high temperatures can be as low as $-10^{14} \mathrm{~Pa} s$ [e.g., Stevenson and Lunine, 1986], several orders of magnitude higher than the viscosities estimated here for flows on Ganymede. Ice viscosity might get as low as $\sim 10^{10} \mathrm{~Pa} \mathrm{~s}$, if cryogenic liquids such as methane are present interstitially [Stevenson and Lunine, 1986]. This suggests that solid-state extrusion of pure water ice is less likely to explain the observed flow features.

Liquid water extrusions could be responsible for much of bright terrain formation [e.g., Allison and Clifford, 1987], as explained above. Brines also generally have waterlike viscosities [Kargel, 1991; Hogenboom et al., 1995]. It is probably very difficult to stiffen a pure water liquid very much, however, due to the strong tendency of water-ice crystals to float and the lack of tendency of water molecules to polymerize. Thus, liquid water extrusions are less likely to explain formation of the observed thicker deposits.

Ammonia-water may be an important minor component of Ganymede's interior [e.g., Lunine and Stevenson, 1982]. The rheology of the ammonia-water eutectic and peritectic liquids resemble that of basalt [e.g., Kargel et al., 1991], and can be expected to mimic its behavior. Supercooling and the presence of significant quantities of suspended crystals can both increase the viscosity of the system by several orders of

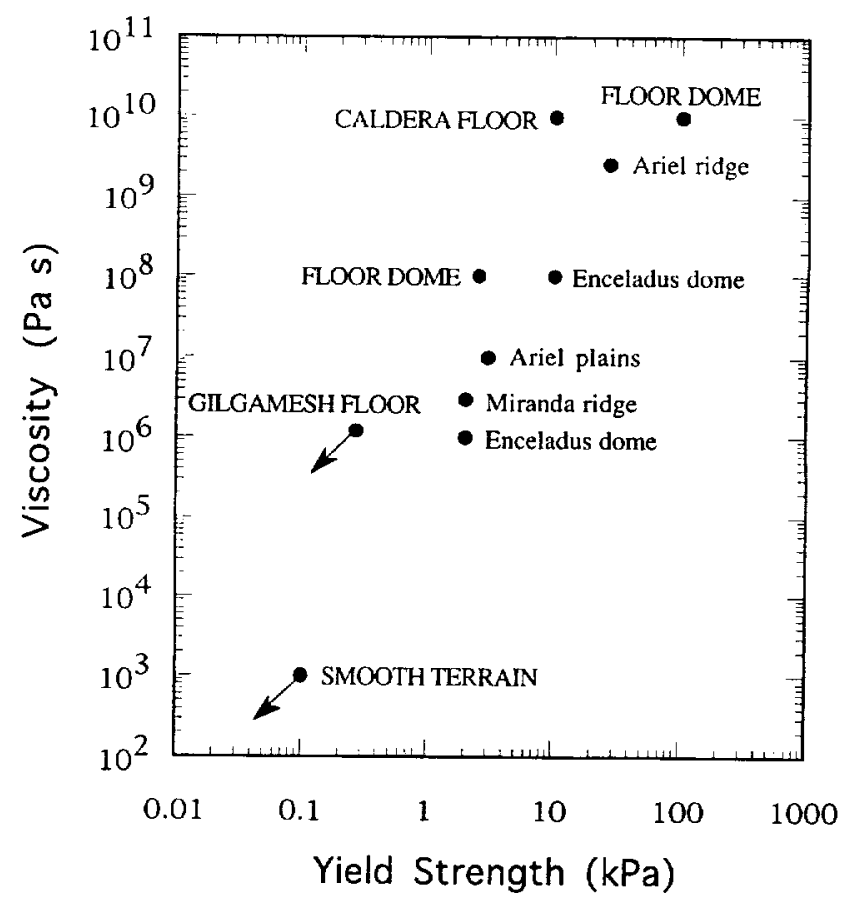

Figure 14. Estimated rheologic properties of volcanic flows on Ganymede and other icy satellites. Values for Miranda and Ariel are from Schenk [1991a]. A number of assumptions are inherent in viscosity estimates, and these can only be regarded as useful in a relative sense. Nevertheless, they indicate a wide range of theologic properties for flows on Ganymede. Arrows indicate values that are upper limits. 
magnitude [e.g., Kargel et al, 1991]. The addition of other soluble substances (a freezing-point depressant such as methanol, for example), can also increase viscosities to values like those of dacites or rhyolites [Kargel et al., 1991], similar to the estimated viscosities reported here. Factors such as long-duration episodic extrusions of low-volume-per-pulse lavas can also significantly affect flow morphology [e.g., Fink et al., 1993], although this type of behavior on Earth is nearly always limited to high viscosity lavas. Ammonia-water lavas, with possible additional constituents or extrusion conditions, could therefore explain the full range of rheologic properties we observe. Other compositional systems may be involved, such as. Crater floor domes and smooth deposits within the caldera-like features therefore are our best evidence for the possible extrusion of melts on Ganymede with higherviscosity, non-water-ice components.

If many of the craters whose topography has been attributed to relaxation are in fact volcanically filled by crater floor domes, then relaxation may be relatively less important than previously thought. Other studies also cast some doubt on the importance of viscous relaxation on Ganymede and Callisto (see discussion by Schenk [this issue]). Relaxation may still be important, however, in some localities or during restricted epochs on Ganymede, Callisto, Enceladus [Passey, 1983], and Ariel [McKinnon et al, 1990]. Reexamination of the role of viscous relaxation in the topography of icy planetary surfaces is necessary.

Our topographic studies indicate that the volcanic history of Ganymede appears to be considerably more complex and longer in duration that previously thought. At least five morphologically (and perhaps compositionally) distinct volcanic styles have been identified on Ganymede in this study. If verified, this volcanic heterogeneity has major implications for the development of a new understanding of the petrological, chemical, and thermal evolution of the interior of Ganymede. This may, in turn, shed light on the role of tidal heating and Ganymede's orbital evolution [Malhotra, 1991]. Acquisition of high-resolution compositional data is one of the primary goals of the Galileo mission. The most important of these tasks is the detection of ice mineralogies other than pure water ice. High-resolution imaging and visible and near-infrared spectroscopic mapping will also resolve many of the ambiguities related to the formation, sequence, and origin of many of these volcanic features.

Acknowledgments. The authors thank Brian Fessler for valuable assistance with the development of automated photogrammetry software, Robert Morris for assistance in updating camera pointing vectors, and Robert Pappalardo and Jeffrey Kargel for pointed and helpful reviews. Lunar and Planetary Institute contribution 863 .

\section{References}

Allison, M.L., and S.M. Clifford, Ice-covered water volcanism on Ganymede, J. Geophys. Res., 92, 7865-7876, 1987.

Blake, S., Viscoplastic models of lava domes, in Lava Flows and Domes: Emplacement Mechanisms and Hazard Implications, edited by J. Fink, pp. 25-46, SpringerVerlag, New York, 1990.

Calvin, W.M., and R.E. Clark, Spectral distinction between the leading and trailing hemispheres of Callisto: New observations, Icarus, 104, 69-78, 1993.

Casacchia, R., and R. Strom, Geologic evolution of Galileo Regio, Ganymede, Proc. Lunar Planet. Sci. Conf. 14th, Part 2, J. Geophys. Res., 89, B419-B428, 1984.
Chester, D.K., A.M. Duncan. J.E. Guest, and C.R.J. Kilburn, Mount Etna, The Anatomy of a Volcano, Stanford Univ. Press, Stanford, Calif., 1985.

Crisp, J., and S. Baloga, A model for lava flows with two thermal components, J. Geophys. Res., 95, 1255-1270, 1990.

Croft, S.K., and L.A. Soderblom, Geology of the Uranian satellites, in Uranus, pp. 561-628, edited by J. Bergstrahl, E. Miner, and M. Matthews, eds., Univ. of Ariz. Press, Tucson, 1991.

Croft, S.K., J.S. Kargel, R.L. Kirk, J.M. Moore, P.M. Schenk and R.G. Strom, The geology of Triton, in Neptune and Triton, edited by D.P. Cruikshank, Univ. of Ariz. Press, Tucson, in press, 1995.

Durham, W.B., H.C. Heard, and S.H. Kirby, Experimental deformation of crystalline $\left(\mathrm{H}_{2} \mathrm{O}\right)$ ice at high pressure and low temperature: Preliminary results, Proc. Lunar Planet. Sci. Conf. I4th. Part 1, J. Geophys. Res., 88, suppl., B377-B392, 1983.

Fink, J.H., Bridges, N.T., and R.E. Grimm, Shapes of Venusian "pancake" domes imply episodic emplacement and silicic composition, Geophys. Res. Lett., 20, 261-264, 1993.

Greenberg, R., S.K. Croft, D.M. Janes, J.S. Kargel, L.A. Lebovsky, J.I. Lunine, R.L. Marcialis, H.J. Melosh, G.W. Ojakangas, and R.G. Strom, Miranda, in Uranus, edited by J. Bergstrahl, E. Miner, and M. Matthews, pp. 693-737, Univ. of Ariz. Press, Tucson, 1991.

Helfenstein, P., Derivation and analysis of geological constraints on the emplacement and evolution of terrains on Ganymede from applied differential photometry, Ph.D. dissertation, 414 pp., Brown Univ., Providence, RI, 1986.

Hillgren, V., and H.J. Melosh, Crater relaxation on Ganymede: Implications for ice rheology, Geophys. Res. Lett., 16. 1339-1342, 1989.

Hogenboom, D.L., J.S. Kargel, J.P. Ganasan, and L. Lee, Magnesium sulfate-water to $400 \mathrm{MPa}$ using a novel piezometer: Densities, phase equilibria, and planetological applications, Icarus, in press, 1995.

Hulme, G., and G. Fielder, Effusion rates and rheology of lunar lavas, Philos. Trans. R. Soc. London, A, 285, 227-234, 1977.

Huppert, H.E., J.B. Shepard, H. Sigudsson, and R.S.J. Sparks, On lava dome growth, with applications to the 1979 lava extrusion of the Soufriere dome of St. Vincent, $J$. Volcanol., 14, 199-222, 1982.

Inge, J.L., and R.M. Batson, Indexes of maps of the planets and satellites 1992, NASA Tech. Memo., 4395, 1992.

Jackson, M.P.A., R.R. Cornelius, C.H. Craig, A. Gansser, J. Stocklin, C.J. and Talbot, Salt diapirs of the Great Kavir, Central Iran, Mem. Geol. Soc. Am., 177, 140 pp., 1990.

Jankowski, D.G., and S.W. Squyres, Solid-state ice volcanism on the satellites of Uranus, Science, 241, 1322-1325, 1988 .

Johnson, T.V., and T.R. McGetchin, Topography on satellite surfaces and the shape of asteroids, Icarus, 18, 612-620, 1973.

Kargel, J.S., Brine volcanism and the interiors of asteroids and icy satellites, Icarus, 94, 368-390, 1991.

Kargel, J., S. Croft, J.1. Lunine, and J.S. Lewis, Rheological properties of ammonia-water liquids and crystal-liquid slurries: Planetological applications, lcarus, 89, 93-112, 1991.

Kirby, S.H., W.B. Durham, M.L. Beeman, H.C. Heard, and M. A. Daley, Inelastic properties of ice $\mathrm{Ih}$ at low temperatures and high pressures, J. Phys., 48, Cl-227-Cl-232, 1987.

Lucchitta, B.K., Grooved terrain on Ganymede, Icarus, 44, $481.501,1980$.

Lunine, J.I., and D.J. Stevenson, Formation of the Galilean satellites in a gaseous nebula, Icarus, 52, 14-39, 1982. 
Malhotra, R., Tidal origin of Laplace resonance and the resurfacing of Ganymede, lcarus, 94, 399-412, 1991.

Malin, M.C., Surfaces of Mercury and the Moon: Effects of resolution and lighting conditions on the discrimination of volcanic features, Proc. Lunar Sci. Conf. 9th, 3395-3409, 1978.

Malin, M.C., Domes on Ganymede (abstract), Reports of the Planetary Geology Program-1980, NASA Tech. Memo., 82385, p. 67, 1980.

McKinnon, W.B., and E.M. Parmentier, Ganymede and Callisto, in Satellites, edited by J. A. Burns and M. S. Matthews, p. 718-763, Univ. of Ariz. Press, Tucson, 1986.

McKinnon, W.B., C.R. Chapman, and K.R. Housen, Cratering of the Uranian satellites, in Uranus, edited by J. Bergstrahl, E. Miner, and M. Matthews, pp. 629-692, Univ. of Ariz. Press, Tucson, 1990.

Melosh, H.J., and D.M. Janes, Icy volcanism on Ariel (technical comment), Science, 245, 195-196, 1989.

Milton, D.J., B.C. Barlow, R. Brett, A.R. Brown, A.Y. Glikson, E.A. Manwaring, F.J. Moss, E.C.E. Sedmik, J. Van Son, and G.A. Young, Gosses Bluff impact structure, Australia, Science, 175, 1199-1207, 1972.

Moore, J.M., and M.C. Malin, Dome craters on Ganymede, Geophys. Res. Lett., 15, 225-228, 1988.

Moore, J.M., and A.P. Zent, Landform degradation and mass wasting on the Galilean satellites, paper presented at Icy Galilean Satellites: An International Conference, San Juan Capistrano Inst., San Juan Capistrano, Calif., Feb. 1-3, 1994.

Murase, T., A.R. McBirney, and W.G. Melson, Viscosity of the dome of Mount St. Helens, J. Volcanol. Geotherm. Res., 24, 193-204, 1985.

Murchie, S.L., and J.W. Head, The evolution of volcanism on Ganymede: Possible importance of a low melting-point volatile, (abstract), Lunar Planet. Sci., XIX, 819-820, 1988.

Murchie, S.L., J.W. Head, and J.B. Plescia, Tectonic and volcanic evolution of dark terrain and its implications for the internal structure and evolution of Ganymede, $J$. Geophys. Res., 95, 10,743-10,768, 1990.

Pappalardo, R.T., and R. Greeley, A review of the origins of subparallel ridges and troughs: Generalized morphological predictions from terrestrial models, J. Geophys. Res., this issue.

Parmentier, E.M., S.W. Squyres, J.W. Head, and M.L. Allison, The tectonics of Ganymede, Nature, 295, 290-293, 1983.

Passey, Q.R., Viscosity of the lithosphere of Enceladus, lcarus, 53, 105-120, 1983.

Passey, Q., and E. Shoemaker, Craters and basins on Ganymede and Callisto: Morphological indicators of crustal evolution, in Satellites of Jupiter, edited by D. Morrison, pp. 379-434, Univ. of Arizona Press, Tucson, 1982.

Poirier, J.P., Rheology of ices: A key to the tectonics of the ice moons of Jupiter and Saturn, Nature, 299, 683-688, 1982.

Pozio, S., and J.S. Kargel, The tectonic and igneous evolution of Enceladus (abstract), Lunar Planet. Sci., $X X, 864-865$, 1989.

Schenk, P.M., Crater formation and modification on the icy satellites of Uranus and Saturn: Depth/diameter and central peak occurrence, J. Geophys. Res., 94, 3813-3832, 1989.

Schenk, P.M., Fluid volcanism on Miranda and Ariel: Flow morphology and composition, J. Geophys. Res., 96, 1887-1906, 1991 a.
Schenk, P.M., Ganymede and Callisto: Complex crater formation and planetary crusts, J. Geophys. Res., 96, 15,635-15,664, $1991 \mathrm{~b}$.

Schenk, P.M., Central pit and dome craters: Exposing the interiors of Ganymede and Callisto, J. Geophys. Res., 98, 7475-7498, 1993.

Schenk, P.M., The geology of Callisto, J. Geophys. Res., this issue.

Schenk, P.M., and W.B. McKinnon, Dark halo craters and the thickness of grooved terrain on Ganymede, Proc. Lunar Planet Sci. Conf. 15th, Part 2, J. Geophys. Res., 90, suppl., C775-C783, 1985.

Schenk, P., and J.M. Moore, 3-D Moons: The Voyager stereo atlas of the outer solar system, (abstract), Lunar Planet Sci., XXIV, 1249-1250, 1993.

Sharp, R.P., Mars: Troughed terrain, J. Geophys. Res., 78, 4063-4072, 1973a.

Sharp, R.P., Mars: Fretted and chaotic terrain, J. Geophys. Res., 78, 4073-4083, 1973b.

Shoemaker, E.M., Update on the impact rates in the Jovian system, paper presented at Icy Galilean Satellites: An International Conference, San Juan Capistrano Inst., San Juan Capistrano, Calif, Feb. 1-3, 1994.

Shoemaker, E.M., B.K. Lucchita, D.E. Wilhelms, J.B. Plescia and S.W. Squyres, The geology of Ganymede, in Satellites of Jupiter, edited by D. Morrison, pp. 435-520, Univ. of Ariz. Press, Tucson, 1982.

Smith, B.A., and the Voyager Imaging Team, The Jupiter system through the eyes of Voyager 1, Science, 204, 951972, 1979a.

Smith, B.A., and the Voyager Imaging Team, The Galilean satellites and Jupiter: Imaging science results from Voyager 2, Science, 206, 927-950, 1979b.

Smith, B.A., and the Voyager Imaging Team, A new look at the Saturn system: The Voyager 2 images, Science, 215 , 504-537, 1982.

Squyres, S.W., Topographic domes on Ganymede: Ice vulcanism or isostatic upwarping, Icarus, 44, 472-480, 1980.

Squyres, S.W., The topography of Ganymede's grooved terrain, Icarus, 46, 156-168, 1981.

Stevenson, D.J., and J.I. Lunine, Mobilization of cryogenic ices in outer solar system satellites, Nature, 323, 46-48, 1986.

Thomas, P., and G. Schubert, Power-law rheology of ice and the retention of craters on Ganymede, J. Geophys. Res., 93, 13,755-13,762, 1988.

Thomas, P.J., and S.W. Squyres, Formation of crater palimpsests on Ganymede, J. Geophys. Res., 95, 19,161$19,174,1990$.

Wilhelms, D.E., Geologic map of the Osiris and Apsu quadrangles of Ganymede, U.S. Geol. Surv. Misc. Inv. Map, in press, 1995.

Wilshire, H.G., T.W. Offield, K.A. Howard, and D. Cummings, Geology of the Sierra Madera cryptoexplosion structure, Pecos County, Texas, U.S. Geol. Surv. Prof. Pap., 599-H, 42 pp., 1972.

P.M. Schenk, Lunar and Planetary Institute, 3600 Bay Area Blvd., Houston, TX 77058 (e-mail: schenk@Ipi.jsc.nasa.gov)

J.M. Moore, Space Sciences Division, and the SETI Institute, NASA Ames Research Center, Moffett Field, CA 94035.

(Received August 31, 1994; revised June 14, 1995; accepted June 15,1995 .) 